\title{
PREVALÊNCIA E ETIOLOGIA INFECCIOSA DA MASTITE BOVINA NA MICRORREGIÃO DE CUIABÁ, MT
}

\author{
Rodrigo Prado Martins, ${ }^{1}$ Josiane Aparecida Gonçalina da Silva, ${ }^{1}$ Luciano Nakazato, ${ }^{2}$ \\ Valéria Dutra ${ }^{2}$ e Edivaldo Sampaio de Almeida Filho ${ }^{1}$ \\ 1. Departamento de Ciências Básicas e Produção Animal, UFMT. E-mail: martinsrp1@gmail.com \\ 2. Departamento de Clínica Médica Veterinária, UFMT.
}

RESUMO

Este trabalho teve como objetivo verificar a prevalência e etiologia infecciosa da mastite bovina em propriedades leiteiras da microrregião de Cuiabá, estado de Mato Grosso. Foram examinadas 108 vacas pertencentes a rebanhos desta microrregião. Em seguida, submeteram-se 279 amostras de leite provenientes de quartos mamários mastíticos a provas microbiológicas. Dos animais examinados, $85,2 \%$ eram portadores de mastite em pelo menos um quarto mamário. O percentual de quartos mamários afetados pela mastite clínica e subclínica foi de 5,8 e $65 \%$, respectivamente. Quanto à etiologia, nos casos de mastite subclínica os agentes causais mais isolados foram Corynebacterium spp. (27,6\%) e Staphylococcus aureus $(21,5 \%)$. Dentre os casos de mastite clínica, isolaram-se com maior freqüência $S$. aureus $(44,0 \%)$ e Corynebacterium spp. (12,0\%). Embora a elevada prevalência de $S$. aureus e Corynebacterium spp. como causadores de mastites corrobore o verificado em estudos realizados em outras regiões do Brasil, a baixa prevalência de bactérias do gênero Streptococcus nos casos analisados difere do observado em tais relatos.

PALAVRAS-CHAVES: Cuiabá-MT, mastite bovina, microrganismos.

\section{ABSTRACT}

PREVALENCE AND INFECTIOUS ETIOLOGY OF BOVINE MASTITIS IN THE MICROREGION OF CUIABÁ, MT, BRAZIL

This study aims to verify the prevalence and infectious etiology of bovine mastitis in dairy farms of the microregion of Cuiabá, state of Mato Grosso, Brazil. One hundred eight cows belonging to herds from this microregion were examined. Afterwards, 279 milk samples from mastitic mammary quarters were submitted to microbiological examinations. Among the examined animals, $85.2 \%$ were carriers of mastitis in one mammary quarter at least. The percentile of mammary quarters affected by clinical and subclinical mastitis was 5.8 and $65 \%$ respectively. Corynebacterium

KEY WORDS: Cuiabá-MT, bovine mastitis, microorganisms.

\section{INTRODUÇÃO}

As mastites, definidas como inflamações da glândula mamária, correspondem a um fator de grande sp. (27.6\%) and Staphylococcus aureus (21.5\%) were the major causative agents among the subclinical infections. Among the clinical cases, S. aureus (44.0\%) and Corynebacterium sp. (12.0\%) were more frequently isolated. Although the high prevalence of $S$. aureus and Corynebacterium sp. as mastitis causatives confirms the results obtained in studies developed in other Brazilian regions, the low prevalence of the genus Streptococcus in the cases analyzed disagrees to those records.

impacto na obtenção de produção leiteira. Essa enfermidade pode ser classificada, conforme a sua manifestação, como subclínica e clínica. Nas mastites clínicas são observadas reações sem alterações macroscópicas 
detectáveis, porém, com alterações químicas e microbiológicas do leite. Já as mastites clínicas são marcadas por respostas inflamatórias mais severas, que resultam em mudanças no aspecto da secreção láctea, mudanças visíveis no tecido mamário e, em alguns casos, efeitos sistêmicos como hipertermia, prostração e tremores musculares (PRESTES et al., 2003).

BARBALHO \& MOTA (2001) relatam que a mastite subclínica apresenta uma maior importância epidemiológica por alastrar-se silenciosamente pelo rebanho sem que sejam percebidas alterações macroscópicas à inspeção do úbere ou de sua secreção. No que diz respeito às mastites clínicas, BRADLEY (2002) aponta estas como as causas mais comuns de morte entre vacas leiteiras adultas e ressalta a sua gravidade nas questões de bem-estar animal, já que quadros de hiperalgesia estão vinculados a episódios agudos de mastite clínica.

Os microrganismos que comumente causam mastite podem ser divididos em dois grupos, baseandose na sua origem: patógenos contagiosos e patógenos ambientais. Os patógenos contagiosos são aqueles adaptados à sobrevivência no interior da glândula mamária. Em contraste, os patógenos ambientais são melhores descritos como invasores oportunistas do úbere, não adaptados a sobreviver no seu interior (WATTS, 1988).

Dentre os patógenos contagiosos mais importantes da mastite bovina estão Staphylococcus aureus, Streptococcus agalactiae, Streptococcus dysgalactiae. Já entre os patógenos ambientais, destacam-se a $E s$ cherichia coli e o Streptococcus uberis (MENDONÇA et al.,1999).

Apesar do advento da pasteurização, a transmissão de patógenos via leite e seus derivados representa um risco durante as falhas neste processo, principalmente no nicho de mercado de produtos lácteos não pasteurizados (BRADLEY, 2002). FAGUNDES \& OLIVEIRA (2004) afirmam que $44 \%$ do leite consumido no Brasil é proveniente do mercado informal, sendo comercializado sem qualquer tratamento térmico ou controle laboratorial. Portanto, a transmissão dos patógenos da mastite e suas toxinas via leite e produtos lácteos corresponde a um risco à saúde do consumidor.

Além da sua importância em saúde pública, fatores como perdas de produção leiteira, custos de tratamento dos casos clínicos, descarte e morte prematura dos animais, somados aos prejuízos da indústria por redução na qualidade e rendimento na fabricação de derivados são responsáveis pelo elevado impacto econômico das mastites (BUENO et al., 2002).

As frequências de mastite clínica e subclínica são parâmetros consagrados na avaliação da sanidade da glândula mamária. Logo, constituem os primeiros a serem considerados para a implantação de um programa de controle da mastite. Além disso, análises microbiológicas são complementares e indispensáveis em um programa de controle desta enfermidade, por possibilitarem o isolamento e a identificação do seu agente etiológico (BUENO et al., 2003).

Segundo o Instituto Brasileiro de Geografia e Estatística (IBGE, 2007), a produção de leite matogrossense sofreu um incremento de aproximadamente 3,3 vezes entre os anos de 1990 e 2006. Tal resultado garantiu a Mato Grosso a posição de décimo estado brasileiro com maior produção leiteira no ano de 2007 (IBGE, 2008). Apesar desse crescimento, poucos estudos na área de sanidade de rebanhos leiteiros têm sido desenvolvidos em Mato Grosso,

Com base no exposto, este estudo teve como objetivo verificar a prevalência e a etiologia infecciosa da mastite bovina na microrregião de Cuiabá, MT, a fim de auxiliar na implementação de medidas de controle e tratamento dessa enfermidade em rebanhos locais.

\section{MATERIAL E MÉTODOS}

Foram utilizadas neste estudo 108 vacas pertencentes aos rebanhos de cinco propriedades leiteiras aleatoriamente amostradas, localizadas na microrregião de Cuiabá, estado de Mato Grosso. Em todas as propriedades adotava-se o sistema de ordenha mecânica e os rebanhos eram compostos por vacas primíparas e pluríparas de diferentes raças e em diferentes estágios de lactação.

O número mínimo de animais a serem amostrados foi calculado através do programa informático WinEpiscope 2.0, considerando-se a população de 16.166 vacas ordenhadas durante o ano de 2005 na microrregião de Cuiabá (MATO GROSSO, 2007). A prevalência esperada adotada foi de $50 \%$, tendo em vista o maior tamanho possível de amostra e a escassez de dados regionais com respeito à prevalência de 
mastite bovina. Além disso, adotaram-se um nível de confiança de $95 \%$ e um erro amostral máximo de $10 \%$. Como resultado, obteve-se um mínimo de 97 vacas a serem examinadas.

O grupo de animais estudados foi obtido por amostragem aleatória simples. Submeteu-se cada vaca a um exame físico geral e da glândula mamária. Posteriormente, realizou-se o teste da caneca telada para o diagnóstico dos casos de mastite clínica e o California Mastitis Test (CMT), para a detecção de mastites subclínicas. A interpretação desses testes foi realizada conforme SCHALM et al. (1971).

Do total de 479 quartos mamários examinados, 279 amostras de leite procedentes de quartos mamários acometidos por mastite clínica ou subclínica foram coletadas e submetidas a provas microbiológicas. Realizaram-se as coletas após a lavagem dos tetos com água e desinfecção com álcool 70\%, acondicionandose aproximadamente $5 \mathrm{ml}$ de leite em tubos de tampa rosqueada previamente esterilizados. Em seguida, as amostras foram transportadas em caixas de material isotérmico contendo gelo reutilizável ao Laboratório de Microbiologia Veterinária da Faculdade de Agronomia e Medicina Veterinária, Universidade Federal de Mato Grosso (FAMEV-UFMT).

Para as análises microbiológicas, as amostras foram semeadas em ágar sangue de carneiro a $5 \% \mathrm{e}$ Agar MacConkey e incubadas por 24/48h em aerobiose. Procedeu-se à identificação dos microrganismos isolados conforme suas características coloniais e morfotintoriais, produção de hemólise e por meio de provas bioquímicas segundo a chave identificação proposta por QUINN et al. (1994).

\section{RESULTADOS E DISCUSSÃO}

Em 92 (85,2\%) das 108 vacas examinadas, foi observada a presença de mastite clínica ou subclínica em pelo menos um quarto mamário. Analisando-se o percentual de quartos mamários afetados, verificou-se a presença de mastite clínica e subclínica em 5,8\% e 65,0\% destes, respectivamente. Foi observado o predomínio de mastites subclínicas nos rebanhos estudados, havendo uma ocorrência 11,2 vezes maior destas em relação às mastites clínicas. O mesmo resultado foi relatado por SÁ et al. (2000) no estado de Pernambuco.
Em um estudo realizado em propriedades situadas em Pirassununga, SP, foram observadas prevalências semelhantes às verificadas neste trabalho, havendo a presença de mastites clínicas em $7,4 \%$ e subclínicas em $63,6 \%$ dos quartos mámarios analisados. Além disso, relatou-se uma relação de 1:15 entre quartos mamários afetados clínica e subclínicamente (BUENO et al., 2002).

MARTINS et al. (2006), ao analisarem a prevalência de mastite subclínica no rebanho de uma queijaria em Nossa Senhora do Livramento, MT, verificaram a presença da enfermidade em $74,2 \%$ dos animais analisados e um percentual de $44,3 \%$ de quartos mamários afetados subclinicamente. Tais achados são inferiores aos verificados neste estudo.

RIBEIRO et al. (2006) citam que um correto controle de mastites deve atingir níveis de ocorrência inferiores a $1 \%$ do rebanho para a sua forma clínica e inferiores a $15 \%$ para as manifestações subclínicas. Portanto, a prevalência de mastite observada neste estudo está além dos índices considerados toleráveis para essa enfermidade e, além disso, acima do verificado em outras regiões do Brasil.

FERREIRA et al. (2007) observaram um percentual de $41,1 \%$ de quartos mamários reagentes ao CMT em Teresina, PI, e RIBEIRO et al. (2006), em análise de rebanhos do estado do Rio Grande do Sul, constataram a presença de mastite subclínica em $31,1 \%$ e de mastite clínica em $1,22 \%$ dos quartos mamários estudados. São relatados percentuais de animais portadores de mastite subclínica de 52,6\% em rebanhos paulistas (LARANJA \& MACHADO, 1994), 43\% no Paraná (PARDO et al., 1999) e 40,4\% em propriedades localizadas no Rio de Janeiro (VIANNI et al., 1992).

Quanto aos microrganismos isolados dos casos de mastite, Corynebacterium spp. (27,6\%), Staphylococcus aureus (21,5\%), Corynebacterium spp. + S. aureus $(6,8 \%)$ e Staphylococcus intermedius $(6,5 \%)$ foram os agentes causais mais prevalentes nas manifestações subclínicas. Dentre os casos de mastite clínica, isolaram-se com maior frequência S. aureus $(44,0 \%)$ e Corynebacterium sp. $(12,0 \%)$ (Tabela 1). 
TABELA 1. Microrganismos isolados dos casos de mastite bovina clínica e subclínica em propriedades leiteiras localizadas na microrregião de Cuiabá, MT

\begin{tabular}{|c|c|c|c|c|}
\hline \multirow{2}{*}{ Microrganismos } & \multicolumn{2}{|c|}{ Mastite subclínica } & \multicolumn{2}{|c|}{ Mastite clínica } \\
\hline & $\mathrm{n}^{\mathrm{a}}$ & $(\%)$ & $\mathrm{n}^{\mathrm{b}}$ & $(\%)$ \\
\hline Corynebacterium spp. & 77 & 27,60 & 3 & 12,00 \\
\hline Staphylococcus aureus & 60 & 21,51 & 11 & 44,00 \\
\hline S. aureus + Corynebacterium spp. & 19 & 6,81 & - & - \\
\hline Staphylococcus intermedius & 18 & 6,45 & - & - \\
\hline Staphylococcus coagulase positiva (SCP) & 9 & 3,23 & - & - \\
\hline $\mathrm{SCP}+$ Corynebacterium spp. & 4 & 1,43 & - & - \\
\hline Micrococcus sp. & 3 & 1,08 & - & - \\
\hline S. aureus $+\mathrm{SCP}$ & 2 & 0,72 & - & - \\
\hline Staphylococcus coagulase negativa (SCN) & 2 & 0,72 & - & - \\
\hline S. aureus + Corynebacterium sp. $+\mathrm{SCN}$ & 2 & 0,72 & - & - \\
\hline S. aureus + Streptococcus uberis & 1 & 0,36 & - & - \\
\hline S. aureus + Streptococcus dysgalactiae & 1 & 0,36 & - & - \\
\hline Streptococcus spp. & 1 & 0,36 & - & - \\
\hline Streptococcus agalactiae + Candida $\mathrm{sp}$. & - & - & 1 & 4,00 \\
\hline S. agalactiae + Corynebacterium $\mathrm{sp}$. & 1 & 0,36 & - & - \\
\hline S. uberis + Micrococcus sp. & 1 & 0,36 & - & - \\
\hline Corynebacterium sp. + Micrococcus sp. & 1 & 0,36 & - & - \\
\hline Corynebacterium sp. + Nocardia sp. & - & - & 1 & 4,00 \\
\hline S. intermedius + Corynebacterium sp. & - & - & 1 & 4,00 \\
\hline Escherichia coli & 1 & 0,36 & - & - \\
\hline $\mathrm{SCP}+$ Proteus vulgaris & 1 & 0,36 & - & - \\
\hline Corynebacterium $\mathrm{sp} .+$ outros microrganismos & 1 & 0,36 & 1 & 4,00 \\
\hline S. intermedius + outros microrganismos & 1 & 0,36 & - & - \\
\hline Outros microrganismos & 5 & 1,79 & 1 & 4,00 \\
\hline Cultura negativa & 68 & 24,37 & 6 & 24,00 \\
\hline Total & 279 & 100 & 25 & 100 \\
\hline
\end{tabular}

a - quartos mamários acometidos por mastite subclínica

b - quartos mamários acometidos por mastite clínica.

Um estudo anterior realizado em uma propriedade localizada na microrregião de Cuiabá constatou uma maior prevalência de bactérias do gênero Staphylococcus nos casos de mastite subclínica. As espécies $S$. intermedius e o $S$. aureus foram as mais isoladas, sendo encontradas em 18,9 e $7,8 \%$ dos casos (MARTINS et al., 2006).

No Brasil, os Staphylococcus, seguidos dos Streptococcus e do Corynebacterium bovis, são citados como os principais microrganismos associados a casos de mastite bovina (BRITO et al., 1999; MENDONÇA et al.,1999). FERREIRA et al. (2007) identificaram o gênero Staphylococcus sp. em 74,60\% dos casos de mastite. LARANJA \& MACHADO (1994a) observaram como os maiores causadores de mastite os Staphylococcus sp. (44,6\%), seguidos por Corynebacterium sp. (15,0\%), Streptococcus sp. $(8,2 \%)$ e leveduras/fungos $(5,4 \%)$.

De acordo com GIANNEECHINI et al. (2002), entre casos de mastite clínica o $S$. aureus foi isolado em 37,5\% dos casos, seguido da Escherichia coli (12,5\%) e dos Staphylococcus coagulase negativa (SCN) (7,5\%). Quanto à etiologia das mastites subclínicas, os patógenos mais isolados foram $S$. aureus, Streptococcus agalactiae, Enterococcus sp., SCN, Streptococcus uberis, Streptococcus dysgalactiae, E. coli e Staphylococcus 
hyicus. MAHZOUNIEH et al. (2003) observaram, com maior frequência entre os casos de mastite, Staphylococcus coagulase positiva (SCP) (51\%), S. agalactiae $(24.62 \%)$ e SCN $(9.04 \%)$.

BARBALHO \& MOTA(2001) relataram que os Staphylococcus sp. corresponderam a $38,76 \%$ do total de agentes isolados, e o gênero Corynebacterium foi isolado com frequência relativamente alta $(27,91 \%)$ nos casos estudados.

Embora o $S$. aureus seja apontado como o principal causador de mastites no Brasil e em outros países (LARANJA \& MACHADO 1994a; MENDONÇA et al., 1999; GIANNEECHINI et al., 2002; RIEKERINK et al., 2006), o presente estudo evidenciou o Corynebacterium spp. como o maior causador de mastite subclínica e o segundo mais prevalente entre os casos de mastite clínica. Este trabalho diferiu dos outros relatos, pela baixa prevalência verificada de bactérias do gênero Streptococcus.

O C. bovis causa primariamente infecções subclínicas e é considerado por alguns autores como um patógeno de significância limitada ou um microrganismo comensal da glândula mamária (HUXLEY et al., 2003). Entretanto, a sua elevada prevalência em infecções intramamárias (BUENO et al., 2003; PITKÄLÄ et al., 2004) e a sua influência negativa na produção leiteira (ZAFALON et al., 1999) sugerem que talvez seja mais apropriado não considerá-lo um patógeno secundário.

O aumento da importância do C. bovis como agente etiológico causador de mastite foi anteriormente relatado por LARANJA \& MACHADO (1994a). Em um estudo no estado de São Paulo, BUENO et al. (2003) relatam um aumento da presença do Corynebacterium spp. como causador de mastites na região em relação a levantamentos realizados na década de 1980.

O aumento da participação do C. bovis como causador de mastites também é relatado por pesquisadores de outros países. PITKÄLÄ et al. (2004) informam uma redução da prevalência de patógenos clássicos como o $S$. agalactiae e o $S$. aureus ao longo dos anos em rebanhos finlandeses. Entretanto, o $C$. bovis e os SCN, considerados tradicionalmente microrganismos de menor patogenicidade, têm se tornado mais frequentes em tais rebanhos.

O C. bovis dissemina-se entre os animais durante o processo de ordenha, caso esta operação não seja conduzida de forma higiênica. Além disso, uma elevada prevalência de infecções intramamárias por $C$. bovis é um indicativo da ausência ou ineficiência da desinfecção dos tetos após a ordenha, processo esse denominado post-dipping (HALTIA et al., 2006). O post-dipping previne eficientemente a infecção cruzada entre vacas, por eliminar, da superfície e do óstio distal do teto, os patógenos contagiosos que possam ter sido transferidos de animais contaminados para animais sadios durante a ordenha (HUXLEY et al., 2003).

Em todas as propriedades analisadas, o postdipping era realizado. Porém, segundo LARANJA \& MACHADO (1994), essa prática muitas vezes não é realizada de forma correta pelos produtores, sendo comuns falhas devido à escolha de produtos inadequados, má aplicação e descuido com a frequência de troca e remoção do produto. A antibioticoterapia nos casos de mastite clínica também era praticada em todas as propriedades. Contudo, é sabido que a antibioticoterapia, quando praticada de forma isolada, não é capaz de proporcionar a manutenção de baixos coeficientes de ocorrência de mastite (LARANJA \& MACHADO, 1994).

Portanto, pode ser deduzido que a elevada ocorrência de $C$. bovis, bem como de outros patógenos contagiosos como o $S$ aureus, verificada neste trabalho, se deve à deficiência nas práticas de manejo, higiene e terapêutica nas propriedades estudadas, em especial durante a desinfecção pós-ordenha dos tetos.

Um plano para o controle de mastites, denominado Five Point Plain ou Programa de Cinco Pontos, é citado por BRADLEY (2002) como o principal responsável pelo controle bem-sucedido da mastite contagiosa no Reino Unido. Tal plano inclui o uso da desinfecção do teto após a ordenha, adoção da terapia da vaca seca em todo o rebanho, rápida identificação e tratamento das mastites clínicas, descarte das vacas cronicamente afetadas e manutenção regular do equipamento de ordenha.

LARANJA \& MACHADO (1994) constataram a eficiência do Programa de Cinco Pontos na manutenção de baixos coeficientes indicadores da prevalência e incidência de mastite em rebanhos situados em São Paulo. A partir deste relato, pode-se inferir a viabilidade das práticas previstas neste programa em outras regiões do Brasil, inclusive no estado de Mato Grosso. 


\section{CONCLUSÕES}

Observou-se uma elevada prevalência de mastite na microrregião de Cuiabá, MT, o que pode representar um risco à saúde de consumidores de produtos lácteos e resultar em perdas econômicas às indústrias de laticínios locais.

O predomínio do Corynebacterium sp. e do $S$. aureus como agentes causais de mastite indica ocorrência de falhas de higiene durante a ordenha e alerta para o risco de animais portadores de mastites atuarem como fonte de infecção para o rebanho.

\section{REFERÊNCIAS}

BARBALHO, T. C. F.; MOTA, R. A. Isolamento de agentes bacterianos envolvidos em mastite subclínica bovina no estado de Pernanbuco. Revista Brasileira de Saúde e Produção Animal, v. 2, p. 31-36, 2001.

BRADLEY, A. J. Bovine mastitis: an evolving disease. The Veterinary Journal, v. 164, n. 2, p. 116-128, 2002.

BRITO, M. A. V. P.; BRITO, J. R. F.; RIBEIRO, M. T.; VEIGA,V. M. O. Padrão de infecção intramamária em rebanhos leiteiros: exame de todos os quartos mamários das vacas em lactação. Arquivo Brasileiro de Medicina Veterinária e Zootecnia, v. 51, n. 2, 1999.

BUENO, V. F. F.; NICOLAU, E. S.; MESQUITA, A. J.; RIBEIRO, A. R.; SILVA, J. A. B.; COSTA, E. O.; COELHO, K. O.; NEVES, R. B. S. Mastite bovina clínica e subclínica, na região de Pirassununga, SP: frequências e redução na produção. Ciência Animal Brasileira, v. 3, n. 2, p. 47-52, 2002.

BUENO, V. F. F. Etiologia e suscetibilidade a antimicrobianos dos agentes da mastite bovina isolados na região de Pirassununga, SP, Brasil. Revista de Patologia Tropical, v. 32, n. 1, p. 33-44, 2003.

FAGUNDES, H.; OLIVEIRA, C. A. F. Infecções intramamárias causadas por Staphylococcus aureus e suas implicações em saúde pública. Ciência Rural, v. 34, n. 4, p. 1315-1320, 2004.

FERREIRA, J. L.; LINS, J. L. H. A.; CAVALCANTE, T. V.; MACEDO, N. A.; BORJAS, A. Prevalência e etiologia da mastite bovina no município de Teresina, Piauí. Ciência Animal Brasileira, v. 8, n. 2, p. 261-266, abr./jun. 2007.

GIANNEECHINI, R. Occurrence of clinical and sub-clinical mastitis in dairy herds in the West Littoral Region in Uruguay. Acta Veterinaria Scandinavica, v. 43, p. 221-230, 2002.
HALTIA, L.; HONKANEN-BUZALSKI, T.; SPIRIDONOVA, I.; OLKONEN, A.; MYLLYS, V. A study of bovine mastitis, milking procedures and management practices on 25 Estonian dairy herds. Acta Veterinaria Scandinavica, v. 48, p. 22-27, 2006.

HUXLEY, J.N. Corynebacterium bovis - friend or foe? BRITISH MASTITIS CONFERENCE, 2003, Garstang, Proceedings... 2003. p. 23-34. Disponível em: $<$ http://www.britishmastitisconference. org.uk/Page9final09-04-16.html>. Acesso em: 15 ago. 2009.

IBGE. Instituto Brasileiro de Geografia e Estatística. Censo agropecuário 2006: resultados parciais. Rio de Janeiro, 2007. Disponível em: <http://www.ibge.gov.br/home/estatistica/economia/agropecuaria/censoagro/2006/agropecuario.pdf $>$. Acesso em: 15 ago. 2009.

IBGE. Instituto Brasileiro de Geografia e Estatística. Produção da pecuária municipal 2007. v. 35. Rio de Janeiro, 2008. Disponível em: <http://www.ibge.gov.br/home/estatistica/economia/ ppm/2007/ppm2007.pdf>. Acesso em: 15 ago. 2009.

LARANJA, L. F.; MACHADO, P. F. Avaliação da efetividade de um programa de controle de mastite bovina em fazendas produtoras de leite B do estado de São Paulo. Scientia Agricola, v. 51, n. 2, p. 569-577, 1994.

LARANJA, L. F.; MACHADO, P. F. Ocorrência de mastite bovina em fazendas produtoras de leite B no estado de São Paulo. Scientia Agricola, v. 51, n. 3, p. 578-585, 1994a.

MAHZOUNIEH, M.; ZADFAR, G.; MAQAMI, S. G.; SHAMS, M. Bacteriological and epidemiological aspects of mastitis in Arak area dairy herds (Iran). In: INTERNATIONAL CONFERENCE ON PRODUCTION DISEASES IN FARM ANIMALS, 11., 2003, Michigan. Acta Veterinaria Scandinavica, Suppl. 98, 2003. Disponível em: < http://www.actavetscand.com/content/pdf/17510147-44-S1-P92.pdf>. Acesso em: 15 ago. 2009.

MARTINS, R. P.; CUNHA NETO, A.; MARQUES, M. R. H. PRADO, R. Etiologia da mastite subclínica em vacas do rebanho de uma queijaria em Nossa Senhora do Livramento, MT. Higiene Alimentar, v. 20, n. 139, p. 104-409, 2006.

MATO GROSSO. Secretaria de Estado de Planejamento e Coordenação Geral. Anuário Estatístico de Mato Grosso - 2006, v. 28. Cuiabá: Central de Texto, 2007.

MENDONÇA, C. L.; FIORAVANT, M. C. S.; SILVA, J. A. B. A.; SOUSA, M. I.; EURIDES, D.; LANGONI, H. Etiologia da mastite bovina: revisão. Veterinária Notícias, v. 5, n. 1, p. $107-$ $118,1999$.

PARDO, R. B.; STURION, D. J.; BASILE, J. R.; CHAVES NETO, A. F.; DUARTE, D. D. S.; FERNANDES, A. A.; YOKOSAMA, 
S. Y.; MENCK, R. C.; GODOY, C. A.; FARINAZZO, A. M.; PANÍCIO, E. M. Levantamento dos agentes etiológicos da mastite bovina na região de Arapongas, PR. Unopar Científica, v. 1, n. $1,1999$.

PITKÄLÄ, A.; HAVERI, M.; PYÖRÄLÄ, S.; MYLLYS, V.; HONKANEN-BUZALSKI, T. Bovine mastitis in Finland 2001: prevalence, distribution of bacteria, and antimicrobial resistance. Journal of Dairy Science, v. 87, p. 2433-2441, 2004.

PRESTES, D. S.; FILAPPI, A.; CECIM, M. Susceptibilidade à mastite: fatores que a influenciam - uma revisão. Revista da Faculdade de Zootecnia, Veterinária e Agronomia, v. 9, n. 1, p. 48-59, 2003.

QUINN, P. J.; CARTER, M. E.; MARKEY, B.; CARTER, G. R. Clinical veterinary microbiology. Virginia: Wolfe, 1994.

RIBEIRO, M. E. R. Ocorrência de mastite causada por Nocardia $s p p$. em rebanhos de unidades de produção leiteira no sul do Rio Grande do Sul. Revista Brasileira de Agrociência, v. 12, n. 4, p. 471-473, 2006.

RIEKERINK, R. G. M. O.; BARKEMA, H. W.; VEENSTRA, S.; POOLE, D. E.; DINGWELL, R. T.; KEEFE, G. P. Prevalence of con- tagious mastitis pathogens in bulk tank milk in Prince Edward Island. The Canadian Veterinary Journal, v. 47, p. 567-572, 2006.

SÁ, M. E. P.; MOTA, R. A.; SOUZA, M. I.; OLIVEIRA, A. A. F. Etiologia da mastite subclínica em bovinos leiteiros do agreste meridional do estado de Pernambuco. Revista Brasileira de Ciência Veterinária, v. 7, n. 2, p. 100-103, 2000.

SCHALM, O. W.; CARROL, E. J.; JAIN, N. C. Bovine mastitis. Philadelphia: Lea \& Febiger, 1971.

VIANNI, M. C. E.; NADER FILHO, A.; LANGENEGGER, J. Freqüência de isolamento de Staphylococcus coagulase positiva e coagulase negativa na mastite subclínica em bovinos e sua influência na produção láctea. Arquivo da Universidade Federal Rural do RJ, v. 15, n. 2, p. 187-192, 1992.

WATTS, J. L. Etiological agents of bovine mastitis. Veterinary Microbiology, v. 16, p. 41-66, 1988.

ZAFALON, L. F.; AMARAL, L. A.; NADER FILHO, A.; OLIVEIRA, J. V. Influência de bactérias do gênero Corynebacterium e estafilococos coagulase positivos e negativos sobre a contagem de células somáticas e a produção láctea de quartos mamários com mastite subclínica. Revista Napgama, n. 6, p. 4-6, 1999.

Protocolado em: 18 nov. 2008. Aceito em: 28 set. 2009. 